\title{
Histological effect of ovariectomy and estrogen replacement on parotid gland of adult albino rat
}

Dalia A. Mohamed, Heba M. Elnegris* and Rania A. Wahdan

*Correspondence: heba31076@yahoo.com

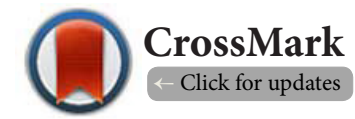

Department of Histology and Cell Biology, Faculty of Medicine, Zagazig University, Egypt.

\begin{abstract}
Introduction: Many women undergo hormone replacement therapy in order to relief the menopausal and postmenopausal symptoms. Oral discomfort is common among these symptoms.

Aim of work: This work aimed to study the possible histological changes of parotid gland associated with ovariectomy and to assess the possible beneficial role of estrogen replacement.

Materials and methods: Thirty healthy adult female albino rats were equally divided into three main groups. Group I: Served as control that was subdivided into two subgroups; the sham operated (Ca) and vehicle-treated $(\mathrm{Cb})$. Group II was the experimental group overiectomized (OVX) one. Group III: was treated with 17_-estradiol (E2) (Teikoku Hormone Mfg. Co., Ltd., $50 \mathrm{mg}$ per day) consecutively for 14 days. At the time of sacrifice, the rats were anaesthetized and specimens from parotid of all rats were stained by $\mathrm{H} \& \mathrm{E}$ and Mallory trichrome stains. The percent of collagen fiber and diameter of ducts were measured. Morphometrical results were statistically analyzed. Immunohistochmical staining for $\mathrm{Cu}, \mathrm{Zn}-\mathrm{SOD}$ was also performed to assess the role of estrogen supplementation.

Results: Examination of parotid in OVX group showed different forms of degenerative changes. The acini appeared irregular and lined with some apoptotic cells. Their cytoplasm contained extensive vacuolations. Homogenous acidophilic material, cellular infiteration within thick CT septa, dilated ducts with stratification in their lining and congestion of blood vessels were also seen. Positive immunostaining for $\mathrm{Cu}, \mathrm{Zn}-\mathrm{SOD}$ appeared in acinar cytoplasm. Ultrastructurally, rarified dilated RER, electron dence and lucent granules were also seen. Estrogen replacement improved the histological changes in treated group.

Conclusion: Results obtained in this study suggest that estrogen deficiency in postmenopausal women lead to variable degenerative changes in parotid salivary glands of adult female albino rats with relative limitation of these changes in estrogen supplemented group.
\end{abstract}

Keywords: Parotid gland, ovariectomy, ultrastructure, estrogen replacement

\section{Introduction}

The average woman lives about one-third of her life beyond menopause and many undergo hormonal replacement therapy to relieve menopausal symptoms. Oral discomfort is a common symptom in these women and may be documented as one of the systemic aspects of menopause [1].

In postmenopausal period the endogenic estrogen level decreases. This is a primary change provides for many characteristic alterations in almost all the body. Estrogen acts through two intracellular receptor proteins called estrogen receptors (ER) [2]. It was reported that ER present in oral buccal mucosa, minor salivary glands, parotid and submandibular glands [3].
The most important and annoying oral affections in menopause are alteration in taste and burning mouth syndrome (BMS). BMS refers to a chronic orofacial pain disorder that occurs in about 1.3 million American women in the postmenopausal period. Hormonal changes may affect the composition or the rate of saliva [4].

Streckfus et al., [5] reported that there was reduction in the salivary flow of submandibular and sublingual glands with the increase in age and reduction in the levels of estrogen production. The ovarian hormones act on the oral mucosa by specific receptors, which select, recognize, and bind the hormone to the cell cytoplasm or nucleus. The deficiency of 
these hormones (estrogen) possibly causes changes in the oral mucosa at the tissue level, because these hormones influence the proliferation, differentiation, and keratinization of the gingival epithelium and stimulate the proliferation of fibroblasts [6].

Sex steroid hormones are known to regulate cell growth, differentiation and function in reproductive as well as nonreproductive tissues [7]. Also, these hormones appear to play a significant role in the physiology of the human oral cavity. A number of studies suggest that oral soft tissues are sensitive to changes in female sex steroid blood levels. So, some diseases and disorders of the oral cavity, show a prediction for women [8], supporting a role for estrogen in disease etiology.

Additionally, it was reported that estrogens are known to modulate epithelial maturation in classic target organs, and similarly, the decrease in estrogen levels during menopause is thought to affect the oral epithelial maturation process, leading to thin and atrophic epithelium prone to inflammatory changes [7].

Oral dryness can lead to considerable difficulty in speaking, eating and tasting, and predispose mucosa to wounds, abrasion and infection. A number of studies have shown that hormone replacement therapy (HRT) can relieve this oral discomfort in postmenopausal women, further suggesting a role for female sex hormones in the maintenance of oral tissues $[\mathbf{9}, \mathbf{1 0}]$.

Apoptosis, i.e., programmed cell death, plays an important role in homeostasis of the body. Previously, it was reported that a reduction of estrogen (belongs to female hormones) could have influence on age-related histological changes in the female rat parotids induced by apoptosis .One component of inducing apoptosis is free radical. Recently, it have been noticed that free radical has an effect on aging.

A living body has superoxide dismutase (SOD), which can eliminate free radical. SOD decreases with aging progress [11].

Together, these observations suggest that estrogens may play an important role in oral mucosal and salivary gland physiology. Even though the salivary glands are not classical targets of female sexual hormones, this study was performed to analyze the influence of the sex hormones on these glands as little is known about this relation.

\section{Materials and methods}

Thirty Female Sprague-Dawley rats, 3 months in age and approximately $120 \mathrm{~g}$ in weight, were used. The animals were housed in individual cages and received a standard diet and tap water ad libitum. The room temperature and humidity were maintained at $23^{\circ} \mathrm{C}$ and $60 \%$, respectively. The light cycle was fixed at $12 \mathrm{~h}$. They were equally divided into three groups; I, II and III.

Group I: was the control (C) that was subdivided into two subgroups; $\mathrm{Ca}$ (sham-operated) and $\mathrm{Cb}$ (vehicle-treated) groups received daily SC injections of sesame oil $(0.1 \mathrm{ml} /$ day).

Group II: was the experimentally induced ovariectomy (OVX).

Group III: was the experimentally induced ovariectomy and received immediate daily subcutaneous (SC) injections of 17-estradiol (E2) dissolved in sesame oil (Teikoku Hormone Mfg. Co., Ltd., Tokyo, Japan) (50 mg per day) consecutively for 14 days (treated) [11].

After 1 week acclimatization in the animal house, each group (10 animals) underwent an operation. The animals were anesthetized with intraperitoneal injection of pentobarbital sodium (15 mg/kg body weight) for the surgical procedure. In the ovariectomized group, small incisions were made on each flank. The ovaries and their surrounding fat were externalized and after ligation of the ovarian arteries the ovaries were removed. The distal ends of each uterine horn were then returned to the peritoneal cavity and the incisions were closed with 4-0 nylon sutures. Each rat received an intramuscular injection of $0.1 \mathrm{ml}$ PenicillinG procaine $(300,000$ unit ml-1, Phoenix Pharmaceutical Inc., St. Joseph, MO) as a prophylactic measure. The sham-operated group underwent a similar surgical procedure, exposing the ovaries but replacing them in the same position.

The animals were sacrificed two weeks after the operation and specimens from right parotid of each animal were fixed in $10 \%$ neutral formol saline for 24 hours and were processed to prepare $5 \mu \mathrm{m}$ thick paraffin sections for haematoxylin and eosin stain and Mallory trichrom stains [12] Also, parts of the same specimens were processed for electron microscope examination [13].

\section{Quantitative morphometric measurements}

Serial sections stained with H\&E and Mallory's trichrome were morphometrically analyzed for detection of diameter of the parotid ducts; area \% of blue stained collagen fibers in the septa, around duct and blood vessels using Leica Qwin 500 image analyzer computer system (Cambridge, England) at Pathology Department, Faculty of Dentistry, Cairo University. The image analyzer consisted of a colored video camera, colored monitor, hard disc of IBM personal computer connected to the Olympus microscope (CX 41) and controlled by Leica Qwin 500 software. The image analyzer was first calibrated automatically to convert the measurement units (pixels) produced by the image analyzer program into actual micrometer units. The measuring frame of a standard area is equal to $7286,78 \mu \mathrm{m}^{2}$. For each parameter ten different non overlapping fields from ten different specimens were examined in each group.

\section{$\mathrm{Cu}, \mathrm{Zn}$-SOD (cupper, zinc superoxide dismutase) immuno- histochemical study}

Deparaffinized sections were incubated in $0.3 \% \mathrm{H} 2 \mathrm{O} 2$ in methanol for $30 \mathrm{~min}$ at room temperature to inhibit endogenous peroxidase activity. The avidin-biotin-peroxidase complex method [14] was performed as follows. The sections were treated in $10 \%$ normal goat serum for $30 \mathrm{~min}$, and incubated in anti-Cu, Zn-SOD anti-serum ( $1.5 \mathrm{mg} / \mathrm{ml}$, Sterssgen) of a dilution of 1:200 for overnight at $4^{\circ} \mathrm{C}$, and then incubated in biotinylated anti-rabbit lgG solution for $30 \mathrm{~min}$ at room 
temperature and the avidin-biotin-peroxidase complex solution of a Vectastain ABC Kit (Vector Laboratories Inc) for $1 \mathrm{~h}$ at room temperature. All the antibody solutions were diluted with $0.01 \mathrm{M}$ phosphate buffer saline ( $\mathrm{pH} 7.4)$. All the sections were then stained with 3.3 diaminobenzidine containing $0.03 \% \mathrm{H} 2 \mathrm{O} 2$. We used fixed reaction times for the processing in all cases. Positive staining was clearly cytoplamic reactivity.

\section{Statistical analysis}

The obtained data from morphometrical analysis were subjected to one way analysis of variance (ANOVA) and post hoc test using Statistical Package for the Social Sciences (SPSS) version 11. The $P$ value $<0.05,<0.001$ and $>0.05$ were considered significant, highly significant and non significant respectively.

\section{Results}

\section{Light microscopic results}

Examination of H\&E stained sections showed that control groups $(\mathrm{Ca} \& \mathrm{Cb})$ had the same structures. The parenchyma of parotid gland was formed of serous acini and duct system. The acini appeared rounded with secretory cells and narrow lumima. They had basal basophilic nuclei and apical acidophilia. The intralobular duct had normal structure. Thin connective tissues appeared around ducts, blood vessels and inbetween the lobules (Figure 1A). Examination of H\&E stained sections of operated group (II) revealed that most of the acini appeared irregular with darkly stained nuclei and many vacuoles in their cytoplasm. They were separated by thickened septa containing cellular infiltration. Homogenous acidophilic material was also seen (Figure 1B). The interelobular ducts were dilated and lined by stratified epithelium. Congested blood vessels were also found (Figure 1C). Examination of H\&E stained sections of treated group (III) showed apparent normal appearance of serous acini and ducts (Figure 1D).

Mallory's trichrome stained sections clarified the occurrence of little collagen fibers inbetween the lobules, around interlobular ducts and blood vessels in parotid gland of group I (Figure 2A). While in group II, collagen fibers of extensive amount appeared in between the lobules and around blood vessels (Figure 2B). Group III revealed moderate amount of collagen fibers (Figure 2C).

Examination of the semithin section of group I revealed the normal appearance of the acini and intrelobular ducts of the gland. The acini were lined by pyramidal cells that had basal vesicular nuclei and apical secretory granules. In between the lobules, the ducts appeared with normal structure (Figure 3A). While examination of group II showed irregular acini with variable sizes. They had apoptotic nuclei and many vacuoles in their

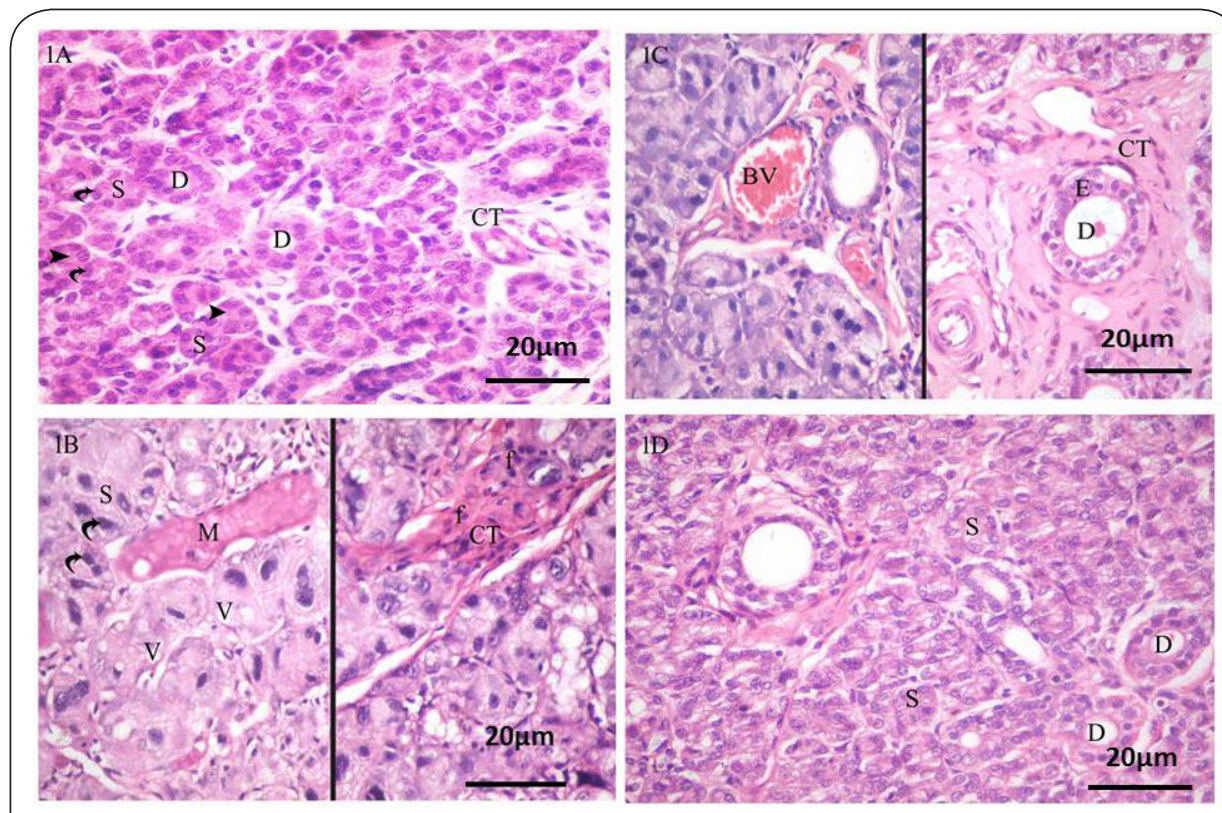

Figure 1. H\&E stained sections.

(A): Control group showing rounded serous acini (S) with narrow luminae. They have basal basophilic nuclei (curved arrow) and apical acidophilia (arrowhead). Note, normal appearance of intralobular ducts (D) and thin septa (CT).

(B): Operated group showing irregular acini (S) with darkly stained nuclei (curved arrow) and cytoplasmic vacuolations (V). Cellular infiltration (f) inside thick connective tissue (CT) septa is also seen. Notice, homogenous acidophilic material (M).

(C): Showing dilated interlobular ducts (D) with stratified epithelial lining (E); prominent thick septa (CT) are also seen. Congestion of blood vessels (BV) is also seen. (D): Treated group showing apparently normal serous acini (S) and intralobular ducts (D) of parotid gland. (Scale bar $=20 \mu \mathrm{m}$ ). 

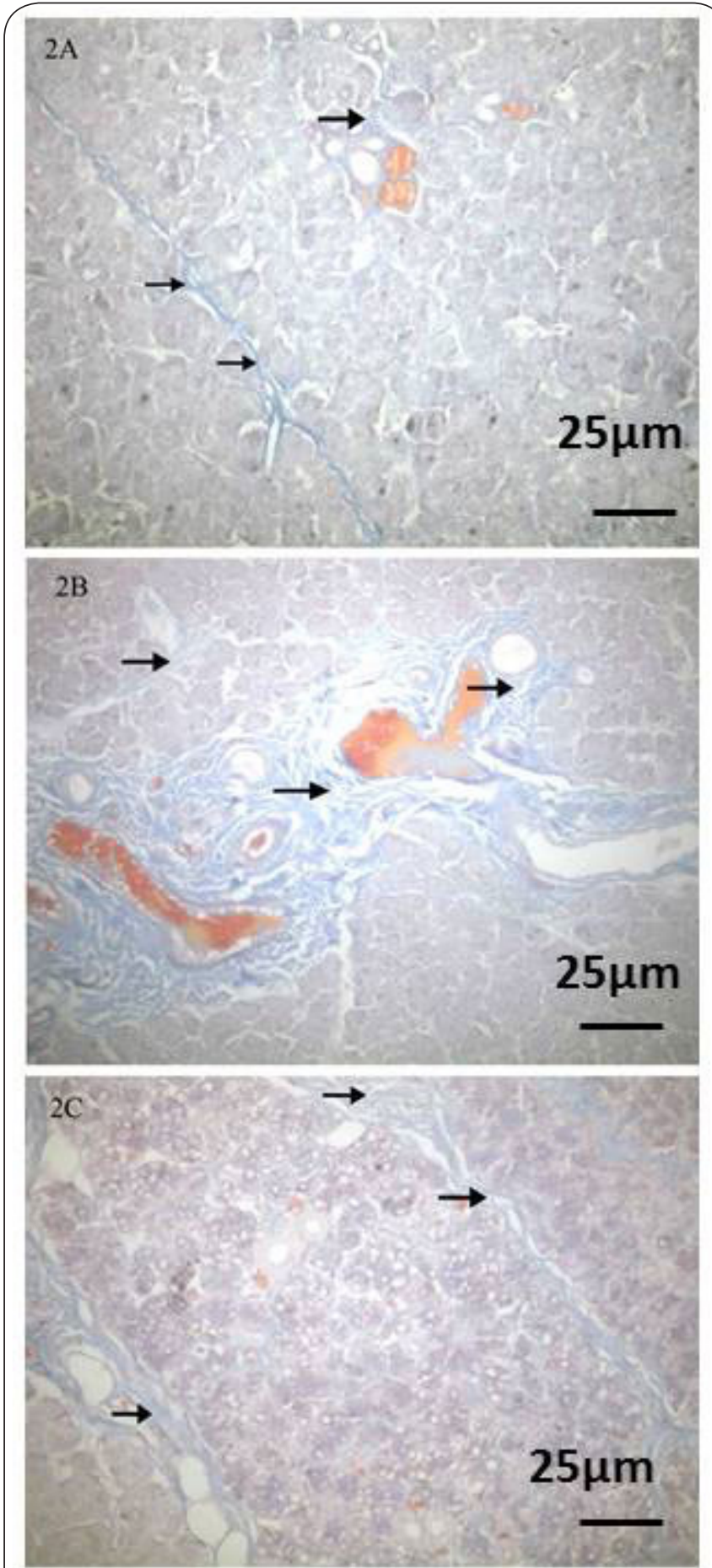

Figure 2. Mallory's trichrome sections.

(A): Control group showing little collagen fibers (arrow) in between the lobules, around interlobular ducts and blood vessels.

(B): Operated group showing increased collagen fibers (arrow) in between the lobules, and around blood vessels.

(C): Treated group showing moderate amount of collagen fibers (arrows) in between the lobules. (Scale bar $=25 \mu \mathrm{m}$ ).

cytoplasm. The acini separated by thick connective tissue septa containing dilated interlobular ducts. Some of the epithelial lining of the ducts appeared with darkly stained nuclei (Figure 3B). Treated group examination showed apparent normal serous and interlobular ducts of parotid gland (Figure 3C). Immunohistochemical stained sections of control group (I) showed positive cytoplasmic reaction for CU,Zn-SOD (Figure 4A). This reaction decreased in ovariectomized group (II) (Figure 4B)
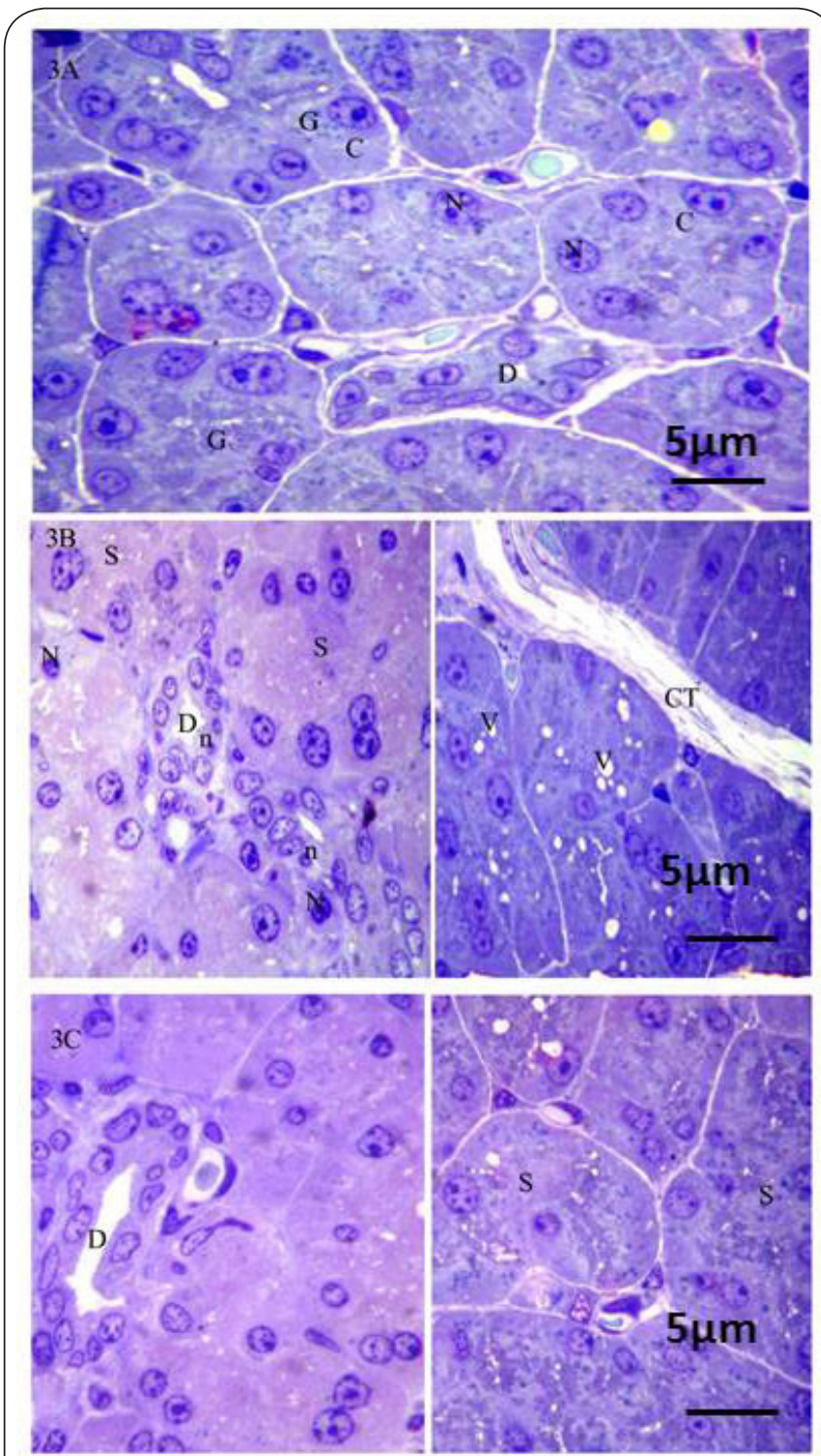

Figure 3. Semithin sections stained with Toulidine blue. (A): Control group showing normal serous acini lined by pyramidal cells $(\mathrm{C})$. They have basal vesicular nuclei $(\mathrm{N})$ and apical secretory granules (G). Note, interlobular duct (D) in between the lobules have normal structure.

(B): Operated group showing irregular variable sized acini (S).They have apoptotic nuclei (N) and vacuolated cytoplasm (V). Thick connective tissue septa are also seen (CT). The interlobular duct (D) has some darkely stained nuclei (n). (C): Treated group showing apparent normal serous acini (S) and interlobular ducts (D) of parotid gland. (Scale bar $=5 \mu \mathrm{m}$ ). 

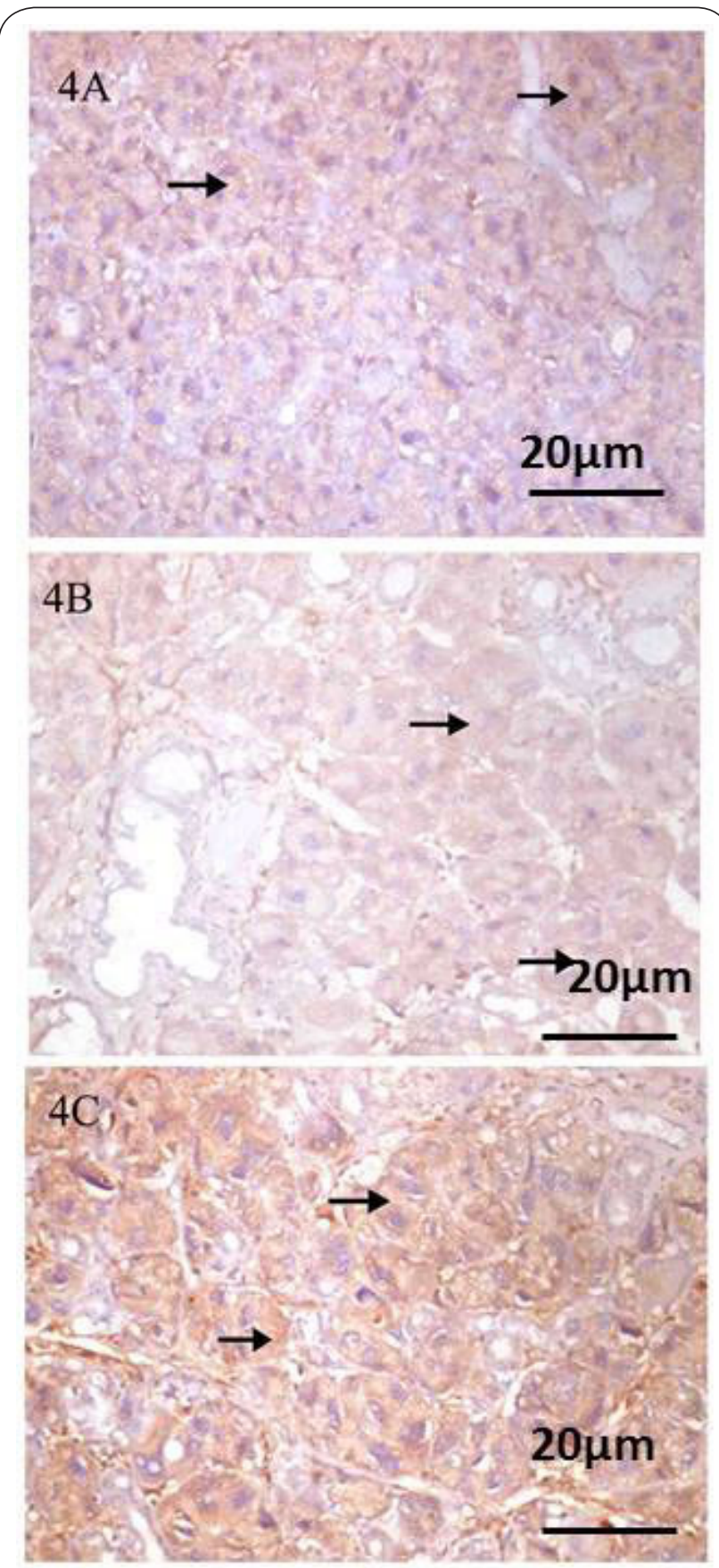

Figure 4. Immunohistochemical stained sections.

(A): control group showing moderate positive immunostaining reaction for $\mathrm{Cu}, \mathrm{Zn}$-SOD (arrow) in cytoplasm of acini.

(B): Operated group showing mild positive immunostaining reaction for $\mathrm{Cu}, \mathrm{Zn}-\mathrm{SOD}$ (arrow) in acinar cell cytoplasm.

(C): Section of treated group showing strong positive immunostaining reaction for $\mathrm{Cu}, \mathrm{Zn}$-SOD (arrow) in acinar cell cytoplasm. (Scale bar $=20 \mu \mathrm{m})$.

and became stronger in treated group (III) (Figure 4C).

\section{Electron microscope results}

Examination of the ultrathin sections of control group (I) showed normal acinar cells with apical electron dense and electron lucent secretory granules, densly packed rough endoplasmic reticulum and mitochondria (Figure 5A). Secretory ducts lined mainly with cuboidal epithelium had rounded nuclei and cytoplasmic granules. They attached together with intercellular desmosomes (Figure 5B). While examination of operated group (II) clarified the presence of apoptotic acinar cells with irregular heterochromatic nuclei, dilated rarified rough endoplasmic reticulum, electron lucent and electron dense secretory granules. Other cells contained extensive vacuoles in their cytoplasm (Figure $\mathbf{5 C}$ ). The ducts of same group contained apoptotic cells with irregular heterochromatic nuclei, many electron dense granules and intercellular desmosomes (Figure $\mathbf{5 C}$ ). On the other hand examination of treated group (III) showed acinar cells with different affection; some appeared apoptotic with heterochromatic nuclei, and others appeared normal. Electron dense and electron lucent granules, rough endoplasmic reticulum were seen in their cytoplasm (Figure 5D). Dilated duct with apparently normal lining cells could be seen (Figure 5E).

\section{Morphometrical results}

The duct diameter and the mean area \% of collagen fiber for all groups were presented in (Table 1 and Figure 6): there was a significant increase $(\mathrm{P}<0.05)$ in collagen \% of OVX group (II) compared with control group (I). While, there was a significant decrease in collagen fiber \% in treated group (group III) as compared with OVX group (group II).

Table 1. Mean values of the area $\%$ of collagen fibers and the duct diameters in the different studied groups.

\begin{tabular}{lll}
\hline Groups & Area \%of collagen fiber & Duct diameter \\
\hline Control(I) & $11.4 \pm 2.24^{\mathrm{n}}$ & $33.3 \pm 10.62^{\mathrm{n}}$ \\
OVX group(II) & $20.51 \pm 4.6^{\mathrm{a}}$ & $65.07 \pm 9.78^{\mathrm{a}}$ \\
Treated group (III) & $14.46 \pm 3.79^{\mathrm{b}}$ & $40.44 \pm 9.2^{\mathrm{b}}$ \\
\hline
\end{tabular}

${ }^{\mathrm{n}}$ non-significant difference with group I

ahighly significant difference with group I

bhighly significant difference with the group II

\section{Discussion}

Several aspects of menopause are universal: hot flashes, excessive transpiration, and vaginal atrophy, caused by estrogen deficiency and manifested in most women after menopause. The systemic aspects of menopause are well documented and include oral manifestations, such as changes in salivary secretion, gingivitis, bleeding, BMS and altered taste sensation [6].

Burning mouth syndrome (BMS) is a relatively common condition with prevalence between 0.7 and $4.6 \%$ of the general population. The etiology of this disorder is poorly understood even though new evidence for a possible neuropathic patho- 


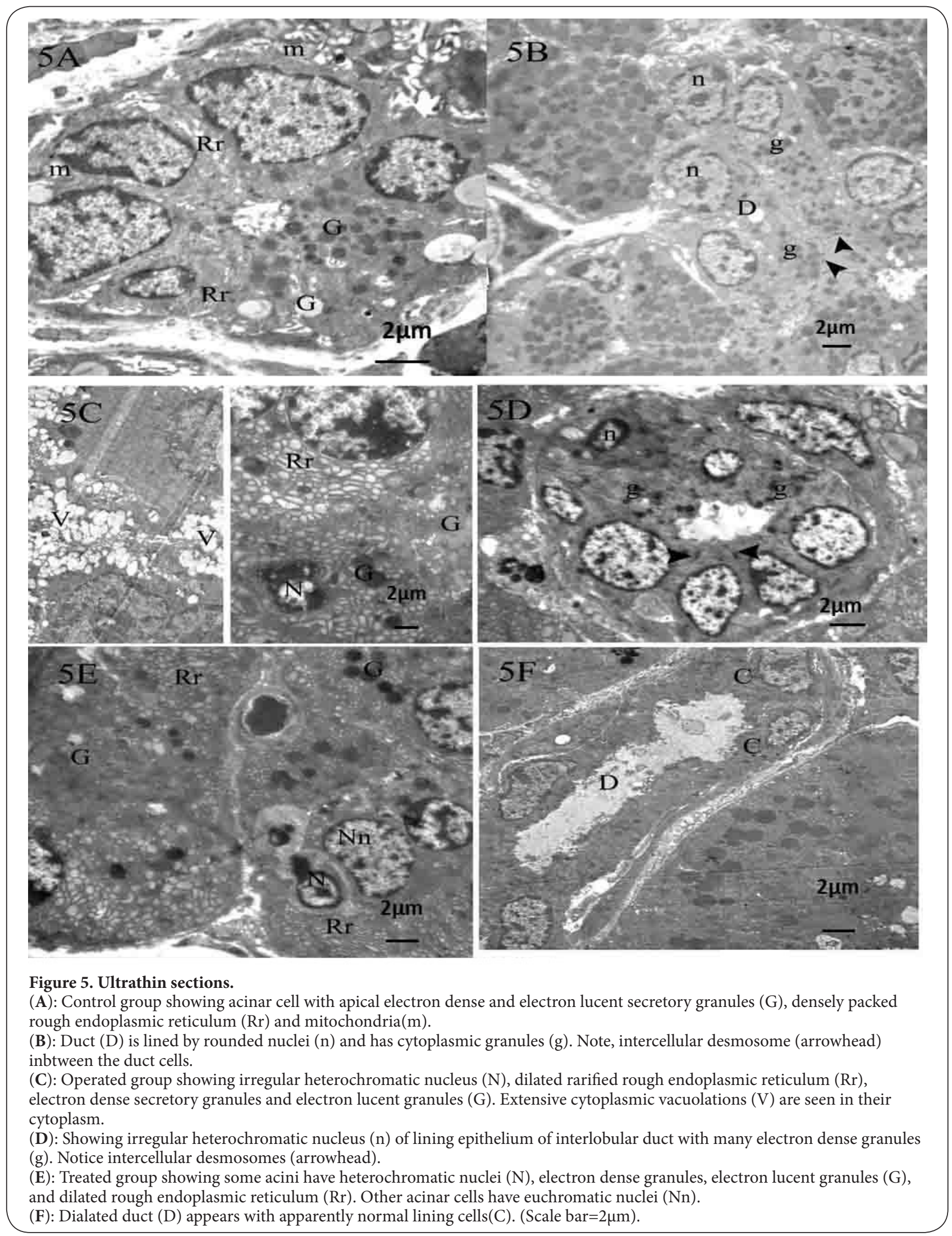




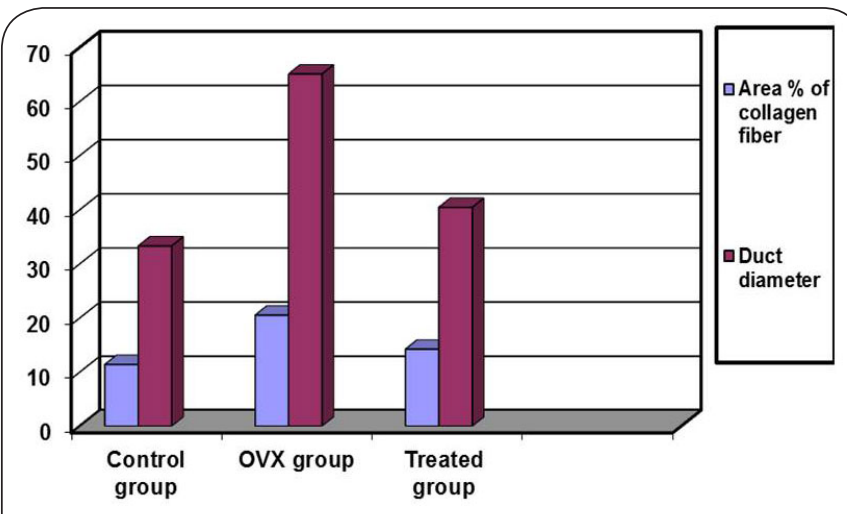

Figure 6. Histogram showing the area \% of collagen fibers and the duct diameters in the different studied groups.

genesis of idiopathic BMS is emerging [4].

Burning mouth syndrome may be primary (idiopathic) $[14,15]$ or secondary condition. Secondary type may be caused by local or systemic disease, including nutritional deficiencies, hormonal changes associated with menopause, local oral infections, and denture-related lesions. Professional delay in diagnosing, referring, and appropriately managing of BMS patients occurs frequently. Treatment should be tailored to each patient to avoid this condition [16-18].

Female sex steroids may have a beneficial effect on the salivary glands [19] and some studies, Hietala [20] \& Laine [21] demonstrate increased saliva flow rate after hormone treatment. During pregnancy, Hormone-related changes of the composition could affect saliva function, increase the severity of gingival inflammation [22] and lead to development of gingival pyogenic granuloma [23].

The results of the present work provide evidence that ovariectomy induces different forms of degenerative changes in parotid gland of group II. Most of the acini appeared irregular with darkly stained nuclei and many vacuoles in their cytoplasm. They were separated by thickened septa containing cellular infiltration. Homogenous acidophilic material was also seen. The interalobular ducts were dilated and lined by stratified epithelium. Congested blood vessels were also found.

These changes were reported by several studies younis [24] \& Stramandinoli-Zanicott et al., [25] who referred them either to denervation of the gland or Hypocellularity, hypovascularity and hypoxia.

Degenerated structures were replaced with homogenous acidophilic areas which detected in gland. These amorphous acidophilic areas were described as hyaline degeneration of duct cells [26] Also, El-Sakhawy\& Saeid [27] reported the same histological changes in parotid gland. Estrogen regulates the balance between endothelial dependent vasoconstrictor and vasodilator influences, possibly via estrogen-specific actions on nitric oxide and prostaglandin (PG2)-dependent pathways. This leads to vasodiltataion of blood vessels and edema [28]. Edema manifested by cellular infilteration within thickened
CT septa and blood vessels congestion [27].

Also, significant dilatation of the parotid ducts was evident by morphometrical analysis of diameters of operated group. Affection of the parotid ducts is related to accumulation of ROS in their lining cells [29]. Collagen fibers appeared in extensive amount in between the lobules and around blood vessels in the same group. Estrogen is antioxidant hormone and acts as radical scavengers and inhibits lipid peroxidation in vivo and in vitro. So, low level of this hormone could lead to oxidative stress in overiectomized rats [30]. RamosDeconte et al., [31] reported that oxidative stress caused increase in collagen fiber in parotid of diabetic rats.

In current work, operated group revealed mild positivity for $\mathrm{Cu}, \mathrm{Zn}$-SOD while this immunoreaction became stronger in treated group. These results in accordance with Kusunoki et al [11]. They reported that administration of estrogen to postmenopausal women will be useful for preventing senile disturbances as osteoporosis, atherosclerosis, Alzheimer;s, etc. Urabe [32], Mortel et al., [33] and Honjo [34] mentioned that estrogen could suppress apoptosis in rat cranial nerve cells [11]. Also some researchers Oztekin et al., [35] reported that estradiol supplementation to ovariectomized rats decreased lipid peroxidation in liver tissue.

Ultrastructurally, parotid gland of operated group (II) clarified the presence of apoptotic acinar cells with irregular heterochromatic nuclei, dilated rarified rough endoplasmic reticulum, electron lucent and electron dense secretory granules. Extensive cytoplasmic vacuoles and apoptotic cells lining their ducts were also found. These results were in accordance with younis [24] and Omar [36] who concluded that generation of large number of free radicals (nitrogen \&oxygen) could damage cellular proteins. Oxidative stress caused by estrogen deficiency in this group is the major factor that induced cellular damage. This damage might trigger the process of apoptosis [30]. Steven and Lowe [37] concluded that, the stagnant secretion in the excretory ducts might be due to mitochondrial affections. This mitochondrial affection lead to depletion of ATP with failure of biosynthesis and membrane pumps and as a result, the cells had no energy for the process of secretion transport.

Moreover, researchers Tirapelli et al., [38] detected these ultrastructural alterations in the parotid glands of alcoholic animals. They explained the presence of cytoplasmic vesicles by the great penetration of fluids in the cytoplasm of the acinar cells. Dilatation of rough endoplasmic reticulum was found in the acinar cells due to alterations in the cytoplasm of the striated ducts [39].

In the current work, examination of treated group (III) showed apparent normal appearance of serous acini and ducts and moderate amount of collagen fibers. The acinar cells appeared with different affection; some appeared apoptotic with heterochromatic nuclei, and others appeared normal. Electron dense and electron lucent granules, rough endoplasmic reticulum were seen in their cytoplasm. Dilated 
duct with apparently normal lining cells could be also seen.

To prove the role of a hormone in the pathogenesis of any disease, firstly, hormone must first exist in the target tissue. Second, the hormone's specific receptor must reside in the target tissue. Third, the absence of the hormone in the target tissue should contribute to the onset of the disease. Finally, the replacement of the hormone should induce the response. It is known that sex steroids exist in saliva [40].

Ovaries are the main source of natural estrogens. Their dysfunction decreases oestradiol level in blood and at the same time its stimulatory function in target tissues. Presence of estrogen receptors in cells of soft tissues causes changes evoked by lack of natural estrogen $[41,42]$. Drugs used in the prevention of postmenopausal osteoporosis and protect body against alterations caused by hypoestrogenism. Prevention of postmenopausal hypoestrogeny can be based not only on simple supplementation with missing hormone, but also drugs modulating estrogen receptors can be used, e.g. raloxifene $[43,44]$. Changes caused by estrogen deficiency are manifested in the vascular, urogenital and skeletal systems. There are many studies about structural and functional changes in the urogenital system in women.

Postmenopausal women frequently use hormonal therapy which elevate estrogen in serum and affect the saliva composition of protein and carbohydrate structure [1]. It was mentioned that a tissue-specific estrogen receptor is widely expressed in both oral epithelium and the salivary glands. Consequently, sex steroid hormone (estrogen) appears to play an important and complex role in the regulation of salivary glands especially ductal cells [7].

It was reported that low estrogen after ovariectomy reflects trophical changes in many organs including salivary glands. Oral discomfort in postmenopausal women may be improved with replacement therapy. Also, this therapy leads to apparent normalizing of oral salivary gland structure. Rahnama et al., [3] and Kusunoki et al., [11] suggested that sex hormone could influence age related histological changes in the parotid gland induced by apoptosis. Recently, administration of estrogen to postmenopausal women reported to be useful for preventing multiple senile disturbances.

The previous results concluded that estrogen deficiency in postmenopausal women lead to variable degenerative changes in parotid salivary glands of adult female albino rats with relative limitation of these changes in estrogen supplemented group. This may constitute an argument for further more complex studies on biological and health consequences of ovariectomized women, to test the necessity to use hormonal replacement during menopause with special recommendation to use estrogen as a protective measure.

\section{Competing interests}

The authors declare that they have no competing interests.

Authors' contributions
\begin{tabular}{|l|c|c|c|}
\hline Authors' contributions & DAM & HME & RAW \\
\hline Research concept and design & $\checkmark$ & $\checkmark$ & $\checkmark$ \\
\hline Collection and/or assembly of data & $\checkmark$ & $\checkmark$ & -- \\
\hline Data analysis and interpretation & $\checkmark$ & -- & -- \\
\hline Writing the article & $\checkmark$ & -- & -- \\
\hline Critical revision of the article & -- & $\checkmark$ & $\checkmark$ \\
\hline Final approval of article & -- & $\checkmark$ & $\checkmark$ \\
\hline
\end{tabular}

Acknowledgement

We would like to thank Dr. Mona El shwadfi for her aid in statistical results.

\section{Publication history}

Editor: Paola Castrogiovanni, University of Catania, Italy. Received: 29-Oct-2015 Final Revised: 30-Nov-2015 Accepted: 10-Dec-2015 Published: 22-Dec-2015

\section{References}

1. Eliasson L, Carlen A, Laine M and Birkhed D. Minor gland and whole saliva in postmenopausal women using a low potency oestrogen (oestriol). Arch Oral Biol. 2003; 48:511-7. | Article | PubMed

2. Carlstedt-Duke J. Cellular estrogen activity: implications for pulsed estrogen therapy. Maturitas. 2001; 38 Suppl 1:S7-S13. | Article | PubMed

3. Rahnama M, Swiatkowski W, Lancut M and Wojcik A. Influence of raloxifene and $17 \mathrm{~B}$-oestradiol on rats' oral mucosal structure. Bull Vet Inst. Pulawy. 2004; 48:329-332. | Pdf

4. Maltsman-Tseikhin A, Moricca P and Niv D. Burning mouth syndrome: will better understanding yield better management? Pain Pract. 2007; 7:151-62. | Article | PubMed

5. Streckfus CF, Baur U, Brown LJ, Bacal C, Metter J and Nick T. Effects of estrogen status and aging on salivary flow rates in healthy Caucasian women. Gerontology. 1998; 44:32-9. I Article I PubMed

6. Seko K, Kagami H, Senga K, Ozeki K, Mizutani H and Ueda M. Effects of ovariectomy and estrogen replacement on rat oral mucosa. Maturitas. 2005; 50:44-51. | Article | PubMed

7. Valimaa H, Savolainen S, Soukka T, Silvoniemi P, Makela S, Kujari H, Gustafsson JA and Laine M. Estrogen receptor-beta is the predominant estrogen receptor subtype in human oral epithelium and salivary glands. J Endocrinol. 2004; 180:55-62. | Article I PubMed

8. Yih WY, Richardson L, Kratochvil FJ, Avera SP and Zieper MB. Expression of estrogen receptors in desquamative gingivitis. J Periodontol. 2000; 71:482-7. | Article | PubMed

9. Forabosco A, Criscuolo M, Coukos G, Uccelli E, Weinstein R, Spinato S, Botticelli $A$ and Volpe A. Efficacy of hormone replacement therapy in postmenopausal women with oral discomfort. Oral Surg Oral Med Oral Pathol. 1992; 73:570-4. I Article I PubMed

10. Eliasson L, Carlen A, Laine M and Birkhed D. Minor gland and whole saliva in postmenopausal women using a low potency oestrogen (oestriol). Arch Oral Biol. 2003; 48:511-7. | Article | PubMed

11. Kusunoki T, Shiraishi H, Murata K, Nishida N and Tomura T. Apoptosis and estrogen on aging changes of female rat parotids. Aging cell Acta Med Kinki Univ., 2004; 29:27-30.

12. Bancroft JD and Gamble M. Theory and Practice of Histological Techniques. $5^{\text {th }}$ ed., Churchill Livingstone. New york, London, Philadelphia. 2002; 125-138.

13. Glauert AM and Lewis PR. Biological Specimen Preparation for Transmission Electron Microscopy. Portland press. London. 1998; 17.

14. Granot $M$ and Nagler RM. Association between regional idiopathic neuropathy and salivary involvement as the possible mechanism for oral sensory complaints. J Pain. 2005; 6:581-7. | Article | PubMed

15. Nagler RM and Hershkovich $\mathrm{O}$. Sialochemical and gustatory analysis in 
patients with oral sensory complaints. J Pain. 2004; 5:56-63. | Article | PubMed

16. Benzon HT, Raja SN and Molloy RE et al. Cervicogenic headache and orofacial pain. In: Phero JC, Bonzon H, ed. Essentials of Pain Medicine and Regional Anesthesia, 2nd ed. Philadelphia: Elsevier. 2005; 301-310. I Article | PubMed Abstract | PubMed Full Text

17. Barker KE and Savage NW.(2005): Burning mouth syndrome: an update on recent Barker KE and Savage NW. Burning mouth syndrome: an update on recent findings. Aust Dent J. 2005; 50:220-3; quiz 288. | Article I PubMed

18. Brown RS, Farquharson AA, Sam FE and Reid E. A retrospective evaluation of 56 patients with oral burning and limited clinical findings. Gen Dent. 2006; 54:267-71. I PubMed

19. Leimola-Virtanen R, Salo T, Toikkanen S, Pulkkinen J and Syrjanen S. Expression of estrogen receptor (ER) in oral mucosa and salivary glands. Maturitas. 2000; 36:131-7. | Article | PubMed

20. Hietala EL, Heikkinen J, Vaananen HK and Larmas M. Effect of postmenopausal estrogen treatment on some diagnostic salivary variables. Ann N Y Acad Sci. 1993; 694:286-8. | Article | PubMed

21. Laine $M$ and Leimola-Virtanen $R$. Effect of hormone replacement therapy on salivary flow rate, buffer effect and $\mathrm{pH}$ on perimenopausal and postmenopausal women. Arch Oral Biol. 1996; 41:91-6. | Article | PubMed

22. Hugoson A. Gingivitis in pregnant women. A longitudinal clinical study. Odontol Revy. 1971; 22:65-84. I PubMed

23. Daley TD, Nartey NO and Wysocki GP. Pregnancy tumor: an analysis. Oral Surg Oral Med Oral Pathol. 1991; 72:196-9. | Article | PubMed

24. Younis R, AbouElkhier M, Mourad M and Elnahas W. Ultrastructural changes in the parotid gland of rats after intraglandular injection of botulinum toxin A. Annals of Oral \&Maxillofacial Surgery. 2013; 1-16.

25. Stramandinoli-Zanicotti RT, Sassi LM, Schussel JL, Torres MF, Funchal $\mathrm{M}$, Smaniotto GH, Dissenha JL and Carvalho AL. Effect of fractionated radiotherapy on the parotid gland: an experimental study in Brazilian minipigs. Int Arch Otorhinolaryngol. 2013; 17:163-7. | Article I PubMed Abstract | PubMed Full Text

26. Cawson RA, Gleeson MJ and Eveson JW. Sialadenitis In: Pathology and surgery of the salivary glands. Oxford Edn Isis Medical Media. 1997; 25-33.

27. El-Sakhawy M and Saeid S. Effect of long term adminsteration of aspartame on the parotid salivary glands of male albino rats. Int. J. of Adv. Res. 2014; 2:850-857.

28. Smith J, Lindsay M, Rahimian R and Anderson L. The influence of estrogen and progesterone on parasympathetic vasodilatation in the rat submandibular gland. Auton Neurosci. 2009; 146:87-94. | Article | PubMed Abstract I PubMed Full Text

29. Wei PF, Ho KY, Ho YP, Wu YM, Yang YH and Tsai CC. The investigation of glutathione peroxidase, lactoferrin, myeloperoxidase and interleukin1beta in gingival crevicular fluid: implications for oxidative stress in human periodontal diseases. J Periodontal Res. 2004; 39:287-93. I Article | PubMed

30. Kiray M, Ergur BU, Bagriyanik A, Pekcetin C, Aksu I and Buldan Z. Suppression of apoptosis and oxidative stress by deprenyl and estradiol in aged rat liver. Acta Histochem. 2007; 109:480-5. | Article | PubMed

31. Deconte SR, Oliveira RJ, Calabria LK, Oliveira VN, Gouveia NM, Moraes Ada $S$ and Espindola FS. Alterations of antioxidant biomarkers and type I collagen deposition in the parotid gland of streptozotocin-induced diabetic rats. Arch Oral Biol. 2011; 56:744-51. | Article | PubMed

32. Urabe S. Estrogen and aging. Adv Obstet Gynecol. 1998; 50:161- 2.

33. Mortel KF and Meyer JS. Lack of postmenopausal estrogen replacement therapy and the risk of dementia. J Neuropsychiatry Clin Neurosci. 1995; 7:334-7. | Article | PubMed

34. Honjo $\mathrm{H}$ and Kikuchi N. Estrogen and Alzheimer's disease. Geriatric Med. 2000; 38:651-8.

35. Oztekin E, Baltaci A, Tiftik A and Mogulkoc R. Lipid peroxidation in ovariectomized and pinealectomized rats: the effects of estradiol and progesterone supplementation. Cell Biochem Funct. 2006.
36. Omar S.M.M. Effect of Aspartame on the Frontal Cortex of Adult Male Albino Rats. A light and Electron Microscopic Study. 2009; 32:346-357. I Pdf

37. Stevens A and Lowe J. Pathology.Firstedition, Alan Stevens/James Lowe Mosby, Baltimore, Philadelphia, Toronto. 1995; 23-33.

38. Tirapelli $L$, Tirapelli $D$ and Schimming B. Ultrastructural alterations of the parotid glands of rats (Rattus norvegicus) submitted to experimental chronic alcoholism. Rev. Chil. Anat. 2001; 19. | Article

39. Sasahara M, Matsuo M, Kakizaki G, Aikawa T, Sato T, Uejima K, Yamada $A$, Saito $M$ and Nakamura $K$. The effect of long term ethanol intake on the parotid gland in rats. Tohoku J Exp Med. 1990; 160:251-75. | Article I PubMed

40. Myers A and Naylor GD. Glossodynia as an oral manifestation of sex hormone alterations. Ear Nose Throat J. 1989; 68:786, 789-90. | Article I PubMed

41. Coleman $H$, Benghuzzi $H$, Tucci $M$ and Cason $Z$. The effects of thyroid and reproductive hormones on the viability of human buccal epithelium. Biomed Sci Instrum. 2001; 37:143-8. I Article I PubMed

42. Leimola-Virtanen R, Pennanen R, Syrjanen $K$ and Syrjanen S. Estrogen response in buccal mucosa -- a cytological and immunohistological assay. Maturitas. 1997; 27:41-5. | Article | PubMed

43. Frolik CA, Bryant HU, Black EC, Magee DE and Chandrasekhar S. Timedependent changes in biochemical bone markers and serum cholesterol in ovariectomized rats: effects of raloxifene $\mathrm{HCl}$, tamoxifen, estrogen, and alendronate. Bone. 1996; 18:621-7. | Article | PubMed

44. Delmas PD. Treatment of postmenopausal osteoporosis. Lancet. 2002; 359:2018-26. | Article | PubMed

Citation:

Mohamed DA, Elnegris HM and Wahdan RA. Histological effect of ovariectomy and estrogen replacement on parotid gland of adult albino rat. J Histol Histopathol. 2015; 2:23. http://dx.doi.org/10.7243/2055-091X-2-23 